\title{
Characteristics and outcomes of patients receiving Hospital at Home Services in the South West of Sydney
}

\author{
Anthony Hecimovic ${ }^{1,2,3}$, Vesna Matijasevic ${ }^{1,2,3}$ and Steven A. Frost ${ }^{3,4^{*}}$
}

\begin{abstract}
Background: Hospital at home $(\mathrm{HaH})$ provides acute or subacute care in a patient's home, that normally would require a hospital stay. HaH has consistently been shown to improve patient outcomes and reduce health care costs. The characteristics and outcomes of patients receiving HaH care across the South Western Sydney Local Health District (SWSLHD) has not been well described. This project aimed to describe the characteristics and outcomes of HaH services across the SWSLHD.
\end{abstract}

Methods: The characteristics of patients referred to HaH between January 2017 and December 2019, the indications for $\mathrm{HaH}$, and representation rates to hospital emergency department (ED) will be presented.

Results: Between January 2017 and December 2019 there was 7118 referrals to the local health district's (LHD) HaH services, among 6083 patients (3094 females, 51\%), median age 56 years (Interquartile range (IQR), 40-69). The majority of indications for $\mathrm{HaH}$ were for intravenous venous (IV) medications $(78 \%, n=5552$ ), followed by post-operative drain management $(11 \%, n=789)$, rehab in the home (RiTH) $(5 \%, n=334)$, bridging anticoagulant therapy $(4 \%, n=261)$, and intraperitoneal medications $(1 \%, n=100)$. The requirement for presentation to an ED for care, while receiving HaH only occurred on 172 (2\%) of occasions. The average length of $\mathrm{HaH}$ treatment was 7-days (IQR 4-16). Rates of presentation to ED for $\mathrm{HaH}$ patients have decreased since 2017, 3.4\% (95\% Cl 2.7-4.2\%), 2018 2.1\% (95\% Cl 1.5-2.8\%), and 2019 1.8\% (95\% Cl 1.3-2.4\%), $p$-value for trend $<0.001$.

Conclusion: Hospital at Home is well established, diverse, and safe clinical service to shorten, or avoid hospitalisation, for many patients. Importantly, avoidance of hospitalisation can avoid many risks that are associated with being cared for in the hospital setting.

Keywords: Hospital at home, Community nursing, And nurse practitioner

\footnotetext{
* Correspondence: steven.frost@health.nsw.gov.au

${ }^{3}$ South Western Sydney Local Health District Centre for Applied Nursing Research, Ingham Institute of Applied Medical Research, Western Sydney

University, 1-3 Campbell street Liverpool, Sydney 2170, Australia

${ }^{4}$ Liverpool Hospital, Sydney, Australia

Full list of author information is available at the end of the article
}

(C) The Author(s). 2020 Open Access This article is licensed under a Creative Commons Attribution 4.0 International License, which permits use, sharing, adaptation, distribution and reproduction in any medium or format, as long as you give appropriate credit to the original author(s) and the source, provide a link to the Creative Commons licence, and indicate if changes were made. The images or other third party material in this article are included in the article's Creative Commons licence, unless indicated otherwise in a credit line to the material. If material is not included in the article's Creative Commons licence and your intended use is not permitted by statutory regulation or exceeds the permitted use, you will need to obtain permission directly from the copyright holder. To view a copy of this licence, visit http://creativecommons.org/licenses/by/4.0/ The Creative Commons Public Domain Dedication waiver (http://creativecommons.org/publicdomain/zero/1.0/) applies to the data made available in this article, unless otherwise stated in a credit line to the data. 


\section{Background}

Hospital at home $(\mathrm{HaH})$ provides acute or subacute care in a patient's home, that normally would require a hospital admission [1]. Substituting for hospital care, $\mathrm{HaH}$ care can include hospital avoidance, fully substituting for in-hospital care, and early discharge followed by care at home, partial substitution [2, 3]. Importantly, $\mathrm{HaH}$ has been shown to improve patients outcomes and reduce health care costs [4-6].

Even though $\mathrm{HaH}$ has become more popular, concerns with safety, availability and cost of in-hospital care, many clinicians have expressed concerns with access to newer technologies and resources that deliver urgent, lifesaving treatment [1]. And, disease specific review of $\mathrm{HaH}$ have not shown consistent benefits [7, 8]. For this reason, ongoing research is needed to assess the local safety and effectiveness of $\mathrm{HaH}$ services. In particular $\mathrm{HaH}$ services are (locally known as Hospital in the Home) commenced in the South West of Sydney in 2008, and currently receive approximately 200-300 patient referrals each month, across the local health district (LHD). South Western Sydney Local Health District (SWSLHD) delivers hospital services to a population of approximately one million people, through five acute public hospitals, that between them, have approximately 230,000 admissions annually. Locally unplanned presentation to hospital while receiving $\mathrm{HaH}$ is considered a key performance outcome.

To date, there hasn't been any formal description of the characteristics and outcomes of patients receiving $\mathrm{HaH}$ care across the SWSLHD. Therefore, this project aims to describe the characteristics of patients receiving $\mathrm{HaH}$ care across the LHD, and the outcomes, in particular, the duration and types of treatment, and unplanned hospital representation rates.

\section{Methods}

\section{Subjects and setting}

South Western Sydney Local Health District delivers hospital services to a population of approximately one million people, through five acute public hospitals that between them have approximately 230,000 adults admissions each year. Approximately 200-300 patients are referred to $\mathrm{HaH}$ each month.

\section{Referral to Hospital at Home services}

Patients across the SWSLHD are referred to $\mathrm{HaH}$ after presenting to an emergency department, or acute in hospitals setting. Patients can also be referred to $\mathrm{HaH}$ by a community based General Practitioner by the Tripe I Hub (The Intake, Information and Intervention service for Primary and Community Care).

\section{Operations of service}

The $\mathrm{HaH}$ service operates across the SWSLHD. The program is overseen by a Nurse Practitioner who also provides resource to both staff and patients. A clinical Nurse Specialist (Grade 2) works with the Nurse Practitioner as well. The service is a collaborative between four Ambulatory Care Services across the area who also supply much of the medical governance [9].

\section{Delivery of Hospital in the Home $(\mathrm{HaH})$ services}

The care of $\mathrm{HaH}$ patients is primarily undertaken by community health centres across the local health district, using a multi-disciplinary team of nurses, allied health and medical staff. Rehab in the home (RiTH), is a recent addition to the services provided by the $\mathrm{HaH}$ Team. The rehab delivered is based around postoperative care and ensures patients can leave hospital post-operatively to receive this care at home.

\section{Outcomes of interest}

Due to the nature of $\mathrm{HaH}$ services being to avoid inhospital care, or reduce length of an episode of hospital care, the main key performance indicator is unplanned hospital presentation while receiving $\mathrm{HaH}$ (i.e. presentation to ED for clinical deterioration, or need for vascular access, or to receive care not available in the community setting).

\section{Statistical analysis}

The characteristics of $\mathrm{HaH}$ admissions are presented using descriptive statistics. Averages of continuous data are presented as median with interquartile range (IQR). Yearly rates of presentation to ED were compared using Poisson regression, and are presented with 95\% confidence intervals (CI) [10]. All levels of statistical significance are set at 0.05 , and all data management and analysis were performed using the $\mathrm{R}$ language for statistical computing [11].

\section{Ethical considerations}

This project was reviewed by the South Western Sydney Local Health District Human Research Ethics Committee (HREC) and was determined to meet the requirements of the Australian National Statement on Ethical Conduct in Human Research (2007). Due to the use of routinely collected hospital separation data, the need for individual patient consent was waived (HREC code - ETH 08739). Permission to access the electronic medical record data was obtained from the Head of Department for Primary and Community Health SWSLHD.

\section{Results}

The characteristics of $\mathrm{HaH}$ admissions between January 1st 2017 and December 31st 2019 are presented in 
Table 1 Characteristics of Hospital in the Home Services, January 2017 to December 2019

\begin{tabular}{|c|c|c|c|c|}
\hline & \multicolumn{3}{|c|}{ Year of referral } & \multirow[t]{2}{*}{ Combined } \\
\hline & 2017 & 2018 & 2019 & \\
\hline Age (yrs), median (IQR) & $58(42,70)$ & $58(42,71)$ & $55(38,68)$ & $57(41,70)$ \\
\hline Females, \% (n) & $49 \%(1202)$ & $52 \%(1146)$ & $51 \%(1257)$ & $51 \%(3605)$ \\
\hline \multicolumn{5}{|l|}{ Indication for HiTH, \% (n) } \\
\hline IV medications & $81 \%(2006)$ & $76 \%(1671)$ & $76 \%(1875)$ & $78 \%(5552)$ \\
\hline Post-op drain & $10 \%(243)$ & $12 \%(257)$ & $12 \%(289)$ & $11 \%(789)$ \\
\hline Rehab in the home & $3 \%(67)$ & $6 \%(125)$ & $6 \%(142)$ & $5 \%(334)$ \\
\hline Bridging therapy & $3 \%(84)$ & $5 \%(99)$ & $3 \%(78)$ & $4 \%(261)$ \\
\hline IP medications & $2 \%(43)$ & $1 \%(23)$ & $1 \%(34)$ & $1 \%(100)$ \\
\hline Other (NP review etc.) & $1 \%(23)$ & $1 \%(20)$ & $2 \%(39)$ & $1 \%(82)$ \\
\hline Length of treatment (days), median (IQR) & $7(4,17)$ & $7(4,18)$ & $7(4,15)$ & $7(4,16)$ \\
\hline Presentation to ED, \% (n) & 3\% (84) & $2 \%(45)$ & $2 \%(43)$ & $2 \%(172)$ \\
\hline
\end{tabular}

Table 1. During this period there was approximately 665,000 hospital separations across the SWSLHD, and 7118 referrals to $\mathrm{HaH}$ services, among 6083 patients (3094 females, 51\%), median age 56 years (IQR, 40-69). The majority of indications for $\mathrm{HaH}$ were for IV medications $(78 \%, n=5552)$, followed by post-operative drain management $(11 \%, n=789)$, rehab in the home $(5 \%, n=$ $334)$, bridging anticoagulant therapy $(4 \%, n=261)$, and intraperitoneal medications $(1 \%, n=100)$. The average length of $\mathrm{HaH}$ treatment was 7-days (IQR 4-16). Presentation to an emergency department for care, while receiving $\mathrm{HaH}$ only occurred on 172 (2\%) occasions, a median of $2.3 \%$ per month (IQR 1.3, 3.1).

Presentation rate to ED, between January 2017 and December 2019, based on indication for $\mathrm{HaH}$ are presented in Table 2. Patients receiving $\mathrm{HaH}$ for Rehab had the highest rates of presentation to ED (4.2\%), and overall rates of presentation to ED for $\mathrm{HaH}$ patients has decreased since 2017, 3.4\% (95\% CI 2.7-4.2\%), 2018 2.1\% (95\% CI 1.5-2.8\%), and 2019 1.8\% (95\% CI 1.3-2.4\%), $p$ for trend $<0.001$.

\section{Discussion}

This study has been able to describe the characteristics and outcomes of patients receiving $\mathrm{HaH}$ services across the SWSLHD between January 2007 and December 2019. The majority of these patients were referred to $\mathrm{HaH}$ for administration of IV medications, but also included management of post-operative drains, bridging of anticoagulant therapy (before and after a surgical admission), and rehab in the home following surgery. Only a very small proportion (3\%) of these patients had a change in their clinical status that resulted in them needing to present to an ED during $\mathrm{HaH}$.

The benefit of $\mathrm{HaH}$ services to avoid hospitalisation has been widely described $[1,2,6]$, and has been shown to be a safe, effective and a cost saving alternative to hospitalisation for a wide range of acute problems $[3,5]$. In particular the $\mathrm{HaH}$ has been shown to be a preferred preference for acute care by patients [6], and as a result both clinical outcomes and patient reported outcomes have been proposed as measures of the quality of care. $\mathrm{HaH}$ services have been associated with lower mortality, reduced risk of hospital readmission, and greater patient and carer satisfaction [1]. However, disease specific review of $\mathrm{HaH}$ have not shown consistent benefits, especially among patients with some chronic conditions $[7,8]$.

The results of this study show a similar low-rate of the need for unplanned presentation to the ED during $\mathrm{HaH}$,

Table 2 Presentation to emergency department, based on indication for HiTH, January 2017 to December 2019

\begin{tabular}{|c|c|c|c|c|}
\hline \multirow[b]{2}{*}{ Indication for $\mathrm{HiTH}, \%(\mathrm{n} / \mathrm{N})$} & \multicolumn{3}{|l|}{ Year of referral } & \multirow[t]{2}{*}{ Combined } \\
\hline & 2017 & 2018 & 2019 & \\
\hline IV medications & $3.2 \%(64 / 2006)$ & $2.0 \%(33 / 1671)$ & $1.6 \%(30 / 1875)$ & $2.3 \%(127 / 5552)$ \\
\hline Post-op drain & $4.9 \%(12 / 243)$ & $2.3 \%(6 / 257)$ & $1.4 \%(4 / 289)$ & $2.8 \%(22 / 789)$ \\
\hline Rehab in the home & $7.5 \%(5 / 67)$ & $3.2 \%(4 / 125)$ & $3.5 \%(5 / 142)$ & $4.2 \%(14 / 334)$ \\
\hline Bridging therapy & $3.6 \%(3 / 84)$ & $2.0 \%(2 / 99)$ & $3.9 \%(3 / 78)$ & $3.1 \%(8 / 261)$ \\
\hline IP medications & $0.0 \%(0 / 43)$ & $0.0 \%(0 / 23)$ & $0.0 \%(0 / 34)$ & $0.0 \%(0 / 100)$ \\
\hline Other (NP review etc.) & $0.0 \%(0 / 23)$ & $0.0 \%(0 / 20)$ & $2.6 \%(1 / 39)$ & $1.2 \%(1 / 82)$ \\
\hline All HiTH, rate $(95 \% \mathrm{Cl})$ & $3.4 \%(2.7-4.2)$ & $2.1 \%(1.5-2.8)$ & $1.8 \%(1.3-2.4)$ & $p$ for trend $<0.001$ \\
\hline
\end{tabular}


among studies in the Australian setting and other parts of the world $[1,12]$. And the indications for $\mathrm{HaH}$ reported in this study were similar to another Australian study [12], with the majority of patients also being referred to $\mathrm{HaH}$ for IV therapy. Importantly, this study has shown a downward trend in the need for presentation to the emergency department during $\mathrm{HaH}$, and increasing number of patients being referred to $\mathrm{HaH}$ for rehab, following surgery, in the home. At a local level the results of this study have highlighted the increasing need for $\mathrm{HaH}$ services and a continued low number of patients with unplanned presentation to ED during $\mathrm{HaH}$ care.

An overall strength of this study is the description of a wide range of $\mathrm{HaH}$ patients, across a local health district, over many years. In particular, the $\mathrm{HaH}$ team provides services to five major hospitals and general practitioners, that supply health services to the one million residents of the south west of Sydney. The potential to miss patient presentations to hospital during $\mathrm{HaH}$, over the study period, was minimised by both active surveillance of patients under $\mathrm{HaH}$ care, by the $\mathrm{HaH}$ team, and an extensive search of the hospital electronic patient records to identify ED presentations.

The results of this study highlight the diverse indications for $\mathrm{HaH}$ services, and their effectiveness to avoid hospitalisation. The implications of the success of $\mathrm{HaH}$ services to shorten, or avoid hospital has many implications for patient safety and outcomes. Importantly, $\mathrm{HaH}$ services in the Australian setting have been attributed with the avoidance of the need for increased numbers of acute hospital beds [13]. Avoidance of hospitalisation will lower the risk of hospital related adverse events, infections, delirium and nutritional problems. And, given the high risk of these events amongst the more vulnerable of the population, the elderly, $\mathrm{HaH}$ services has many potential direct and indirect benefits.

\section{Conclusion}

Hospital at Home Services across the South Western Sydney Local Health District are predominately for administration of IV medications, but include management of post-operative drains, bridging of anticoagulant therapy, and rehab in the home. Importantly, only a very small proportion (3\%) of $\mathrm{HaH}$ episodes will include the need for patients to present to ED. Hospital in the Home is well established, diverse, and a safe clinical service to shorten, or avoid hospitalisation for many patients. Importantly, avoidance of hospitalisation can avoid many risks that are associated with being cared for in the hospital setting.

\section{Abbreviations}

Cl: Confidence interval; ED: Emergency department; HaH: Hospital at home; HiTH: Hospital in the home; HREC: Human Research Ethics Committee; IQR: Interquartile range; IV: Intravenous; LHD: Local health district;
RiTH: Rehab in the home; SWSLHD: South Western Sydney Local Health District

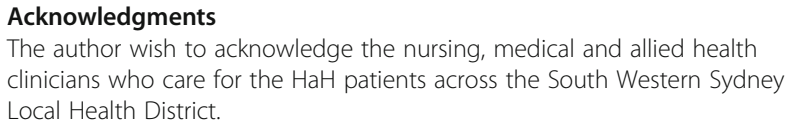

\section{Authors' contributions}

$\mathrm{AH}$, conceptualization, methodology data curation, interpretation of results and preparation of manuscript; VM conceptualization, methodology data curation, interpretation of results and preparation of manuscript; SF conceptualization, methodology data management and analysis, interpretation of results and preparation of manuscript. All authors have read and approve the manuscript.

\section{Funding}

No funding was obtained to support this project.

\section{Availability of data and materials}

The datasets used and/or analysed during the current study available from the corresponding author on reasonable request.

\section{Ethics approval and consent to participate}

This project was considered by the South Western Sydney Local Health District Human Research Ethics Committee and was determined to meet the requirements of the National Statement on Ethical Conduct in Human Research (2007). Due to the use of routinely collected hospital separation data, the need for individual patient consent was waived (HREC code - ETH 08739). Permission to access the electronic medical record data was

obtained from the Head of Department for Primary and Community Health.

Consent for publication

Not Applicable.

\section{Competing interests}

All authors have no potential or actual competing interests to declare.

\section{Author details}

${ }^{1}$ Rosemeadow Community Health Centre, Sydney, Australia. ${ }^{2}$ Primary and Community Health South Western Sydney Local Health District, Sydney, Australia. ${ }^{3}$ South Western Sydney Local Health District Centre for Applied Nursing Research, Ingham Institute of Applied Medical Research, Western Sydney University, 1-3 Campbell street Liverpool, Sydney 2170, Australia. ${ }^{4}$ Liverpool Hospital, Sydney, Australia.

Received: 18 June 2020 Accepted: 18 November 2020 Published online: 26 November 2020

\section{References}

1. Caplan GA, et al. A meta-analysis of "hospital in the home". Med J Aust. 2012;197(9):512-9.

2. Shepperd S, et al. Admission avoidance hospital at home. Cochrane Database Syst Rev. 2008:4:CD007491.

3. Shepperd S, et al. Early discharge hospital at home. Cochrane Database Syst Rev. 2009;1:CD000356.

4. Cryer $\mathrm{L}$, et al. Costs for 'hospital at home' patients were 19 percent lower, with equal or better outcomes compared to similar inpatients. Health Aff (Millwood). 2012;31(6):1237-43.

5. Shepperd S, lliffe S. Hospital at home versus in-patient hospital care. Cochrane Database Syst Rev. 2005:3:Cd000356.

6. Federman $A D$, et al. Association of a Bundled Hospital-at-Home and 30-Day Postacute transitional care program with clinical outcomes and patient experiences. JAMA Intern Med. 2018;178(8):1033-40.

7. Langhorne $P$, et al. Early supported discharge services for stroke patients: a meta-analysis of individual patients' data. Lancet. 2005:365(9458):501-6.

8. Ram FSF, et al. Hospital at home for patients with acute exacerbations of chronic obstructive pulmonary disease: systematic review of evidence. BMJ. 2004;329(7461):315. 
9. New South Wales Ministry of Health, Adult and Paediatric Hospital in the Home Guideline, G.a.S.D. Clinical/patient services - aged care, infectious and M.T. diseases, editors. North Sydney: HSW MOH; 2018.

10. Breslow NE, Day NE. Statistical methods in cancer research. Lyon: International Agency for Research on Cancer; 1980.

11. R Core Team. R: a language and environment for statistical computing. Vienna: R Foundation for statistical computing; 2017.

12. Montalto M, Portelli R, Collopy B. Measuring the quality of hospital in the home care: a clinical indicator approach. Int I Qual Health Care. 1999;11(5): 413-8.

13. Montalto M. The 500-bed hospital that isn't there: the Victorian Department of Health review of the Hospital in the Home program. Med J Aust. 2010; 193(10):598-601.

\section{Publisher's Note}

Springer Nature remains neutral with regard to jurisdictional claims in published maps and institutional affiliations.

Ready to submit your research? Choose BMC and benefit from:

- fast, convenient online submission

- thorough peer review by experienced researchers in your field

- rapid publication on acceptance

- support for research data, including large and complex data types

- gold Open Access which fosters wider collaboration and increased citations

- maximum visibility for your research: over $100 \mathrm{M}$ website views per year

At BMC, research is always in progress.

Learn more biomedcentral.com/submissions 